directs attention through his book to the scope and utility of what is rapidly developing into an important section of organic chemistry.

The topics covered by Prof. Schönberg include photo-isomerism; photo-dimerization; photochemical oxidation reactions; addition reactions with olefins and acetylenes ; photochemical reactions involving ketones, acids, acyl halides, anthracene derivatives, organic halides, etc.; cyclization reactions; photohalogenation; and photochemical reactions of nitric oxide, nitro-compounds, diazo-, diazonium-, and azo-compounds, sulphur, arsenic, and mercury compounds. Reactions leading to the formation of high polymers are excluded as being outside the scope of the book. Prof. G. O. Schenk's chapter on equipment available on the Continent is of less interest to British chemists than other chapters, but will nevertheless provide useful ideas for the design of photochemical reactors and other apparatus. The book was completed in mid-1957, and literature up to the end of 1957 is included as an appendix.

Experimental details are given for numerous syntheses, and the high yields often obtained will encourage many organic chemists ; however, it will often be necessary to read the original literature to ensure that the correct technique is being used.

Many of the reactions described involve free radicals as intermediates, and although a brief summary of the mechanism or the probable course of the reaction is often given, the author wisely restrains himself from over-emphasizing this aspect, and concentrates on the preparative use of photochemistry. For full appreciation of the very many reactions discussed it will thus be necessary for a newcomer to the field to read a standard text on freeradical chemistry.

This book is a useful addition to chemical literature, even though the approach is essentially-and sometimes disappointingly-non-critical. The printing and general lay-out are excellent, making the book easy to read and to use for reference. Some will doubtless wish for an English translation; most would prefer a price lower than $£ 52 s .0 d$. (4 $\frac{1}{2} \mathrm{~d}$. a page).

R. N. Haszeldine

\section{CHEMICAL NOMENCLATURE}

An Introduction to Chemical Nomenclature

By Dr. R. S. Cahn. Pp. viii +96. (London: Butterworths Scientific Publications, 1959.) 10s. $6 d$.

$\mathrm{T}$

THE ever-increasing tempo of scientific research the world over creates pari passu new problems of communications between scientists. New phenomena providing evidence of a multiplicity of yet smaller and more perplexing sub-atomic particlesthe traditional domain of the physicist; new matter at molecular level formed by the almost infinite range of permutations and combinations of the near hundred atoms of the periodic table-the chemist's field; each demands the utmost care in selecting terms with which to describe them if a scientific Babel is to be avoided. In the field of chemistry the International Union of Pure and Applied Chemistry has, through its various nomenclature committees, sponsored much excellent and fruitful study to which Dr. Cahn from Great Britain has contributed in no small measure. The present booklet is timely, especially in view of recent new developments in inorganic chemistry and the concomitant nomenclature changes. While there are no major changes of principle in organic nomenclature, it is in the inorganic field that older chemists will have to accustom themselves to some radical departures from old familiar names for common substances if they are to be systematic. But the Union is realistic when it refers to a system as "in use but not recommended" and Dr. Cahn is not remote from everyday chemical life when he says, "Probably it will die hard, for ferrous chloride comes more glibly off the older tongue than iron (II) chloride or ferrum (II) chloride or even iron dichloride; but it will probably die in time". So did Charles II.

Throughout, Dr. Cahn treats the intractable problem of reconciling usage with system in a friendly sympathetic style and pedantry rarely obtrudes. The principles are clearly stated and it should be possible for the chemist arriving at the substance $\mathrm{NaH}\left(\mathrm{PHO}_{2} \mathrm{~F}_{2}\right)$ to describe it correctly in his paper to the Chemical Society as sodium hydrogenhydrido-dioxodifluorophosphate, and equally for another chemist searching the indexes in the years to come to find and identify the entry. But much remains to be done, especially with the inorganic heterocycles involving $\mathrm{P}, \mathrm{N}, \mathrm{B}$, $\mathrm{Si}, \mathrm{S}$ and the rest, and Dr. Cahn and his colleagues would no doubt prefer that chemists did not spawn exotic new compounds unless they could be given a proper systematic name before a trivial (and possibly misleading) name gained currency in the literature. There is a challenge for the nomenclature or theoretical research chemist to outstrip his experimental colleague and prepare the name ready for the substance.

The organic section lucidly states current principles but contains one or two disconcerting errors. Thiocresol $\mathrm{C}_{6} \mathrm{H}_{4} \mathrm{Me}$. SH could surely never have the systematic name toluene- $\omega$-thiol nor has glycollic acid ever been $\mathrm{HO}_{\mathrm{CH}} \mathrm{CH}_{2} \cdot \mathrm{CH}_{2} \cdot \mathrm{COOH}$. Dr. Cahn rarely nods and he should correct these errors. To perplex chemists there is a Mitford-like disapproval of 'mesyl' while 'tosyl' appears to be 'U' in some places. Half a guinea for such a small booklet is the price for quality, not bulk.

H. J. BARBER

\section{ELECTRONIC STRUCTURE OF MOLECULES}

Die Methoden der Molekülphysik und ihre Anwendungsbereiche

Von H. Preuss. (Fortschritte der Physik, 1 Sonderband.) Pp. vii + 167. (Berlin : Akademie-Verlag, 1959.) 22 D.M.

GIRST of all, the title is wrong. For despite its 1 label this is not an account of the methods of molecular physics. If it were, it would contain some discussion of statistical mechanics, perturbation theory, properties of angular momentum and of spin, influence of electric and magnetic fields on molecules, etc. In fact it is solely concerned with the electronic structure of molecules, the techniques used and the type of result obtained.

Dr. Preuss is already well known to workers in the field of the wave mechanies of molecules as the author of a series of three books containing the numerical values of the various Coulomb and exchange integrals which play such a large part in it. The present book could be regarded as a compendium of the fundamental methods which are involved when using these integrals. 